\title{
Sensitization of osteosarcoma cells to death receptor-mediated apoptosis by HDAC inhibitors through downregulation of cellular FLIP
}

\author{
K Watanabe ${ }^{1,2}, \mathrm{~K}$ Okamoto $^{1}$ and S Yonehara ${ }^{\star, 1}$ \\ ${ }^{1}$ Graduate School of Biostudies and Institute for Virus Research, Kyoto \\ University, Kyoto, Japan \\ 2 Current address: School of Biomedical Science and Medical Research \\ Institute, Tokyo Medical and Dental University, Tokyo 113-8510, \\ Japan \\ * Corresponding author: S Yonehara, Graduate School of Biostudies and \\ Institute for Virus Research, Kyoto University, Shogoin Kawahara-cho 53, \\ Sakyo-ku, Kyoto 606-8507, Japan. Tel: + 8175751 4783; \\ Fax: + 8175751 4784; E-mail: syonehar@ virus.kyoto-u.ac.jp
}

Received 24.2.04; revised 22.7.04; accepted 28.7.04; published online 12.11.04 Edited by $\mathrm{H}$ Ichijo

\begin{abstract} FLIP mRNA.

Cell Death and Differentiation (2005) 12, 10-18.

doi:10.1038/sj.cdd.4401507

Published online 12 November 2004
\end{abstract}

Fas-mediated apoptosis plays an important role in elimination of tumor cells in vivo, but some tumor-derived cells are resistant to this mechanism. Here, we show that treatment with the histone deacetylase (HDAC) inhibitor FR901228 renders Fas-resistant osteosarcoma cell lines sensitive to Fas-mediated apoptosis by downregulating expression of cellular FLIP (cellular FLICE-inhibitory protein), an inhibitor of Fas-mediated activation of caspase-8. Moreover, sensitization to Fas-mediated apoptosis was also induced in Fas-resistant osteosarcoma cells by suppressing FLIP expression using FLIP-specific RNA interference. HDAC inhibitors including FR901228 were shown to induce downregulation of cellular FLIP through inhibiting generation of FLIP mRNA, rather than stimulating degradation at either protein or mRNA level, and the inhibition was independent of de novo protein synthesis. These results clearly indicate that some tumor cells exhibit a phenotype resistant to death receptor-mediated apoptosis by expressing cellular FLIP, and that HDAC inhibitors sensitize such resistant tumor cells by directly downregulating cellular

Keywords: apoptosis; Fas; FR901228; FLIP; histone deacetylase inhibitor; TRAIL; death receptor

Abbreviations: FADD, Fas-associated death domain; FasL, Fas ligand; FLICE, FADD-like interleukin 1-converting enzyme; FLIP, cellular FLICE-inhibitory protein; FLIP-L, long form of FLIP; FLIP-S, short form of FLIP; GFP, green fluorescence protein; HDAC, histone deacetylase; PE, phycoerythrin; TUNEL, terminal deoxynucleotidyltransferase-mediated dUTP nick end labeling; TRAIL, TNF-related apoptosis-inducing ligand; Z-VAD-fmk, benzyloxycarbonyl-Val-Ala-Asp[Ome]-fluoromethylketone

\section{Introduction}

Apoptosis is a form of cell death essential to embryonic development and maintenance of homeostasis. ${ }^{1,2}$ While apoptotic dysfunction underlies various pathologies, including autoimmune and neurodegenerative diseases, apoptosis plays an especially important role in suppressing oncogenesis. Tumor-suppressor genes have been shown to induce apoptosis, which can be triggered by abnormal progression of the cell cycle caused by cellular or viral oncogenes, and defects in proapoptotic genes frequently result in tumorigenesis. $^{3}$

Histone acetylation, which is regulated by the balance of histone acetyltransferase and histone deacetylase (HDAC), plays an important role in regulation of gene expression by modulating chromatin structure. In general, acetylation and deacetylation of histones have been considered to be associated with transcriptional activation and repression, respectively. ${ }^{4,5}$ HDAC inhibitors, which have been reported to cause not only cell cycle arrest and differentiation but also apoptosis, can inhibit proliferation and survival of tumor cells. ${ }^{6}$ Consequently, various HDAC inhibitors, including the natural cyclic depsipeptide FR901228, ${ }^{7-10}$ are under clinical development as novel drugs for cancer therapy. ${ }^{6}$

Apoptosis has been shown to be induced through two main signaling pathways. These are referred to as the intrinsic and extrinsic pathways, and are mediated by the mitochondria ${ }^{11}$ and by death receptors ${ }^{12}$ such as Fas (Apo-1/CD95), ${ }^{13}$ respectively. Apoptosis is executed by effector caspases, such as caspase- 3 and caspase-7, which are in turn activated by cleavage by initiator caspases, such as caspase-8/FADDlike interleukin 1-converting enzyme (FLICE) and caspase-9. The proforms of caspase- 8 and caspase- 9 are initially activated by autocatalytic cleavage in death receptormediated and mitochondria-mediated apoptosis, respectively. Some classes of HDAC inhibitors have been reported to induce apoptosis by activating either caspase-8 or caspase-9 in various types of tumor cell lines.

Molecular mechanisms of Fas-induced apoptosis have been intensively studied. Stimulation of Fas by Fas ligand (FasL) $)^{12,14}$ or agonistic anti-Fas antibody ${ }^{13,15}$ induces recruitment of the Fas-associated death domain (FADD) and procaspase-8, leading to activation of caspase-8 by autocatalytic cleavage of procaspase-8. ${ }^{14,16}$ Activated caspase-8 cleaves and activates either effector caspases or the proapoptotic Bcl-2 family member protein, Bid. Cleaved Bid translocates to the mitochondria and induces activation of caspase-9, leading to the activation of effector caspases. ${ }^{16}$ Importantly, Fas-mediated apoptosis has been reported to be inhibited by cellular FLICE-inhibitory protein (FLIP), through suppression of either recruitment of procaspase-8 by FADD or autocatalytic activation of caspase-8. ${ }^{17}$ Cellular FLIP can be present in short and long forms (FLIP-S and FLIP-L, 
respectively), which are two splicing variants encoded by the same gene.

HDAC inhibitors have been reported to induce apoptosis through either the intrinsic or extrinsic apoptotic pathway. ${ }^{6}$ In HDAC inhibitor-induced activation of death receptor-mediated apoptosis, upregulation of Fas and FasL occurs in cells derived from neuroblastoma, ${ }^{18}$ promyelocytic leukemia, ${ }^{19}$ and uveal melanoma. ${ }^{20}$ In addition, downregulation of FLIP$\mathrm{L}$ protein was reportedly induced by treatment of chronic lymphocytic leukemia cells with the HDAC inhibitors FR901228 and MS-275. ${ }^{21,22}$ Recently, we demonstrated that FR901228 not only induces upregulation of FasL but also shows synergistic apoptosis-inducing activity when costimulated with anti-Fas mAb in osteosarcoma cell lines. ${ }^{23}$ Here, we show that the synergistic effect of FR901228 and anti-Fas $\mathrm{mAb}$ is mediated by FR901228-induced sensitization of Fasresistant osteosarcoma cell lines to Fas-induced apoptosis, and that this sensitization is directly induced by FR901228induced downregulation of FLIP-S and FLIP-L at the mRNA level. These results show that some tumor cells develop resistance to Fas-mediated apoptosis by expressing FLIP, and that treatment with FR901228 renders such Fas-resistant tumor cells sensitive to Fas-induced apoptosis by downregulating the expression of FLIP.

\section{Results}

\section{HDAC inhibitors sensitize tumor cell lines to Fas- induced apoptosis}

We recently reported that the HDAC inhibitor FR901228 induces both activation of Fas-mediated signaling and expression of FasL in osteosarcoma cells, ${ }^{23}$ and simultaneous stimulation with FR901228 and agonistic anti-Fas mAb shows synergistic induction of apoptosis in osteosarcoma cell lines. To clarify whether FR901228 induces sensitization of cells to Fas-induced apoptosis, we examined the effects of pretreatment with FR901228 on Fas-induced apoptosis. The osteosarcoma cell lines OST and U-2 OS were pretreated with FR901228 for $12 \mathrm{~h}$, and then stimulated with agonistic antiFas mAb CH-11. While neither $\mathrm{CH}-11$ alone nor FR901228 alone induced significant apoptosis in these cell lines, pretreatment with more than $2 \mathrm{nM}$ of FR901228 highly sensitized the cells to agonistic anti-Fas mAb-induced apoptosis (Figure $1 \mathrm{a}$ and $\mathrm{b}$ ). In addition, simultaneous stimulation with FR901228 and $\mathrm{CH}-11$ induced more rapid apoptosis in FR901228-pretreated cells than in cells that had not undergone pretreatment, and stimulation with $\mathrm{CH}-11$ alone similarly induced apoptosis in FR901228-pretreated OST cells after washing out of FR901228 (data not shown). These results indicate that treatment with FR901228 renders Fas-resistant osteosarcoma-derived cells sensitive to Fasinduced apoptosis.

We also examined the effects of pretreatment with FR901228 on Fas-sensitive HeLa cells, in which the functions of p53 and $\mathrm{Rb}$ are inhibited. As shown in Figure 1a, HeLa cells pretreated with FR901228 rapidly showed enhanced apoptosis after Fas stimulation. The pan-caspase inhibitor Z-VAD-fmk (benzyloxycarbonyl-Val-Ala-Asp[Ome]-fluoromethylketone) was shown to completely inhibit cell death a
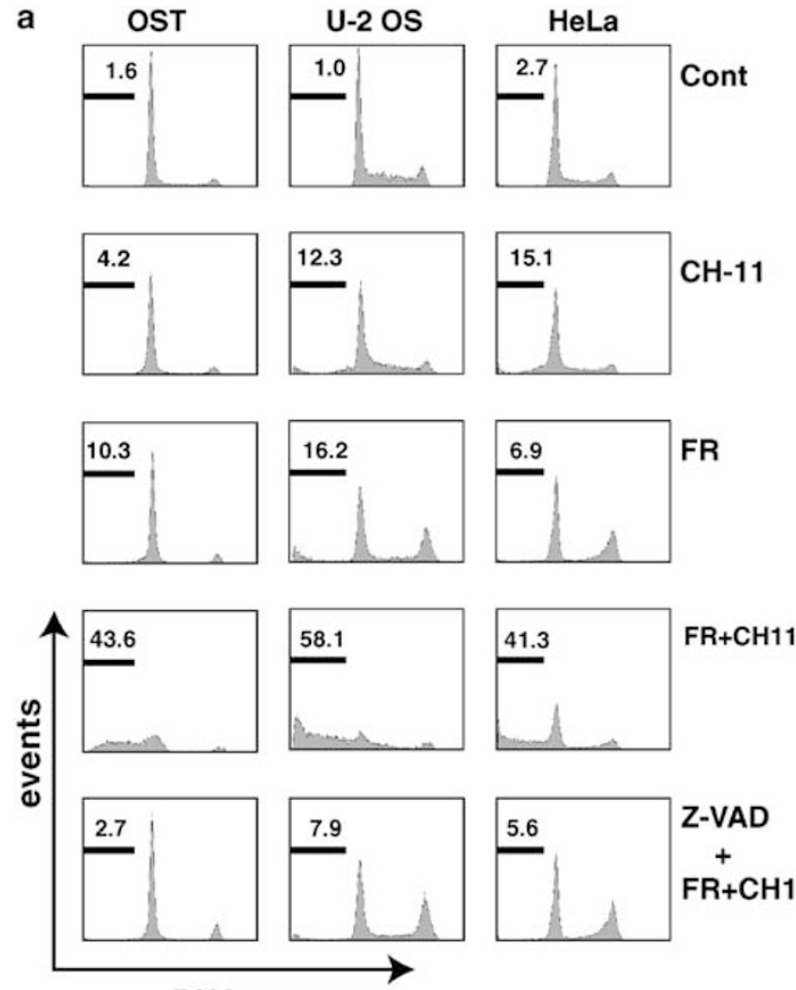

Z-VAD $\mathrm{FR}+\mathrm{CH} 11$

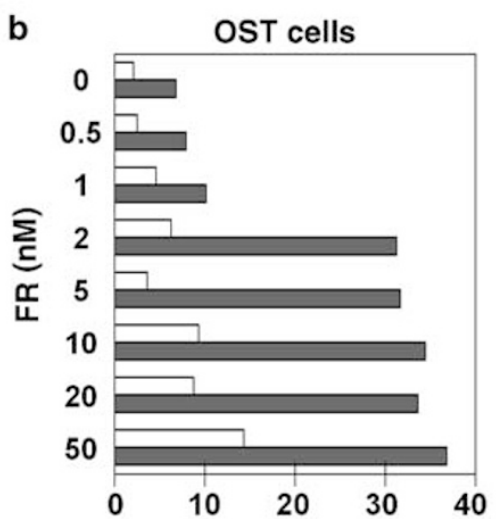

(\%)

Figure 1 Sensitization of tumor cell lines to Fas-induced apoptosis by pretreatment with FR901228. (a) OST, U-2 OS, and HeLa cells were pretreated with (FR) or without (Cont) $10 \mathrm{nM}$ FR901228 for $12 \mathrm{~h}$, and were then stimulated with $250 \mathrm{ng} / \mathrm{ml}$ agonistic anti-Fas $\mathrm{mAb} \mathrm{CH}-11$ for 12,24 , and $3 \mathrm{~h}$, respectively, in the presence or absence of $25 \mu \mathrm{M}$ Z-VAD-fmk. After staining with PI, the number of subdiploid cells was quantified by flow cytometry, and is indicated as a percentage of the total cells in the figures. At least $1 \times 10^{4}$ cells were analyzed for each sample. Representative data are shown from at least three independent experiments. (b) After $12 \mathrm{~h}$ treatment with (black bars) or without (white bars) the indicated amounts of FR901228, OST cells were stimulated with $250 \mathrm{ng} / \mathrm{ml}$ agonistic anti-Fas mAb CH-11 for $12 \mathrm{~h}$. The number of subdiploid cells was analyzed by flow cytometry, and is indicated as a percentage of the total cells. Representative data are shown from at least three independent experiments

induced by Fas stimulation in FR901228-pretreated OST, U-2 OS, and HeLa cells, indicating that cell death is occurring through caspase-dependent process, which is apoptosis. We also examined the effects of pretreatment of OST cells with two other HDAC inhibitors, $10 \mathrm{nM}$ Trichostatin A and $20 \mathrm{mM}$ 


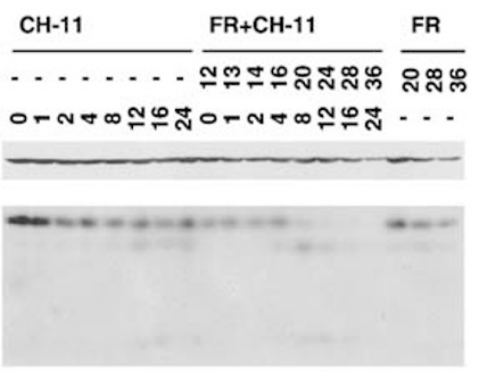

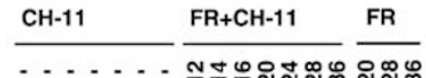

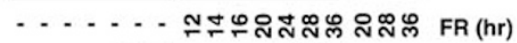

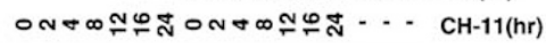

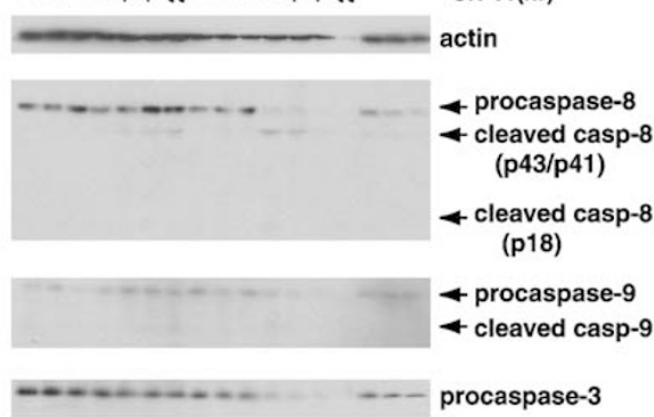

Figure 2 Western blot analysis of caspases in Fas-stimulated tumor cell lines pretreated with FR901228. OST (a) and U-2 OS (b) cells were treated with $10 \mathrm{nM}$ FR901228 (FR) or $250 \mathrm{ng} / \mathrm{ml}$ anti-Fas mAb CH-11 alone for the indicated time, or pretreated with $10 \mathrm{nM} \mathrm{FR901228} \mathrm{(FR)} \mathrm{for} 12 \mathrm{~h}$ and then stimulated with $250 \mathrm{ng} / \mathrm{ml}$ anti-Fas mAb CH-11 in the presence of FR901228 for the indicated time. Cell lysates were analyzed by Western blotting with anti-caspase-8, anti-caspase-9, and anticaspase-3 Abs

sodium butyrate, and the results indicated that these HDAC inhibitors also sensitize OST cells to Fas-induced apoptosis (data not shown).

To examine whether FR901228 stimulated Fas-induced activation/cleavage of caspases, Western blot analysis was performed for caspase-8, caspase-9, and caspase-3 in OST and U-2 OS cells (Figure 2). While treatment of these cells with $\mathrm{CH}-11$ alone or FR901228 alone induced very little cleavage of these proteins, Fas stimulation after pretreatment with FR901228 significantly induced cleavage of caspase-8, -9 , and -3 , and consequently the amounts of procaspase-8, -9 , and -3 decreased after $8 \mathrm{~h}$ treatment with $\mathrm{CH}-11$. These results indicate that FR901228 induces sensitization of tumor cell lines to Fas-mediated apoptosis by facilitating cleavage of caspases.

\section{FR901228 downregulates expression of FLIP-S and FLIP-L at the protein level}

To examine whether regulation of cell surface Fas expression is involved in FR901228-induced sensitization of cells to Fasmediated apoptosis, we analyzed the cell-surface expression level of Fas before and after treatment with FR901228 (Figure 3a). The results showed that cell-surface Fas expression was unchanged in OST, U-2 OS, and HeLa cells after treatment with FR901228 for $24 \mathrm{~h}$. This indicates that FR901228 sensitizes cells to Fas-induced apoptosis by affecting the signaling pathway downstream of Fas. Hence, we analyzed the expression levels of molecules downstream from Fas in Fas-signaling pathways by Western blot analysis with antibodies specific for FADD, caspase-8, caspase-3, FLIP, Bid, Bax, Bcl-2, and Bcl-X (Figure 3b). FR901228 did not upregulate or downregulate the expression levels of FADD, caspase-8, caspase-3, Bid, Bax, Bcl-2, and Bcl- $\mathrm{X}_{\mathrm{L}}$, while expression of FLIP-S and FLIP-L were highly downregulated after treatment of OST, U-2 OS, and HeLa cells with FR901228 for $8 \mathrm{~h}$. More than 2 nM FR901228 was shown to effectively downregulate the expression of FLIP-S in OST cells (Figure $3 \mathrm{c}$ ), indicating that the concentration of FR901228 to downregulate FLIP coincides well with that to sensitize OST, U-2 OS, and HeLa cells to Fas-induced apoptosis (Figure 1b).

We recently reported that FR901228 induces expression of FasL in OST cells. Since Fas ligation by FasL can lead to downregulation of FLIP-L and FLIP-S by caspase-8-dependent cleavage and recruitment of FLIP-S to FADD, respectively, we examined the effect of anti-Fas neutralizing $\mathrm{mAb}$ ZB-4 on the FR901228-induced downregulation of FLIP-L and FLIP-S (Figure 3d). Although $500 \mathrm{ng} / \mathrm{ml}$ of ZB-4 effectively blocked Fas-mediated apoptosis (data not shown), ZB4 never affected FR901228-induced downregulation of FLIP-L and FLIP-S. Thus, FR901228-induced downregulation of FLIP is independent of the induction of FasL.

\section{Downregulation of FLIP is sufficient for sensitization of cells to Fas-induced apoptosis}

To evaluate the role of FR901228-induced downregulation of FLIP in Fas-mediated apoptosis in OST cells, we tried to suppress the expression of both FLIP-S and FLIP-L using the RNA interference (RNAi) method with a pSUPER vector system. Five kinds of RNAi constructs (pSUPER flip-1, -2, -3, -4 , and -5 ; see Materials and Methods) were designed against FLIP mRNA, which corresponded to common sequences between CDNAs of FLIP-S and FLIP-L. Western blot analysis indicated that pSUPER flip-1, flip-4, or flip-5, and a mixture of them effectively decreased the levels of both FLIP-S and FLIP-L protein, while pSUPER flip-2 and -3 produced only a slight decrease in the FLIP-S and FLIP-L protein level (Figure 4a).

We then analyzed the sensitivity of RNAi vector-transfected OST cells to Fas-mediated apoptosis. Cells were cotransfected with expression vectors for green fluorescence protein (GFP) and the RNAi constructs against FLIP, and Fasinduced activation of caspase-3 was quantified in GFPpositive cells (Figure 4b and c). RNAi-induced downregulation 
of both FLIP-S and FLIP-L clearly sensitized OST cells to Fasmediated activation of caspase-3, and the sensitivity was comparable to that of cells pretreated with FR901228. In contrast, overexpression of FLIP-S and FLIP-L conferred resistance to Fas-induced apoptosis in OST cells pretreated with FR901228. In addition, downregulation of FLIP by RNAi
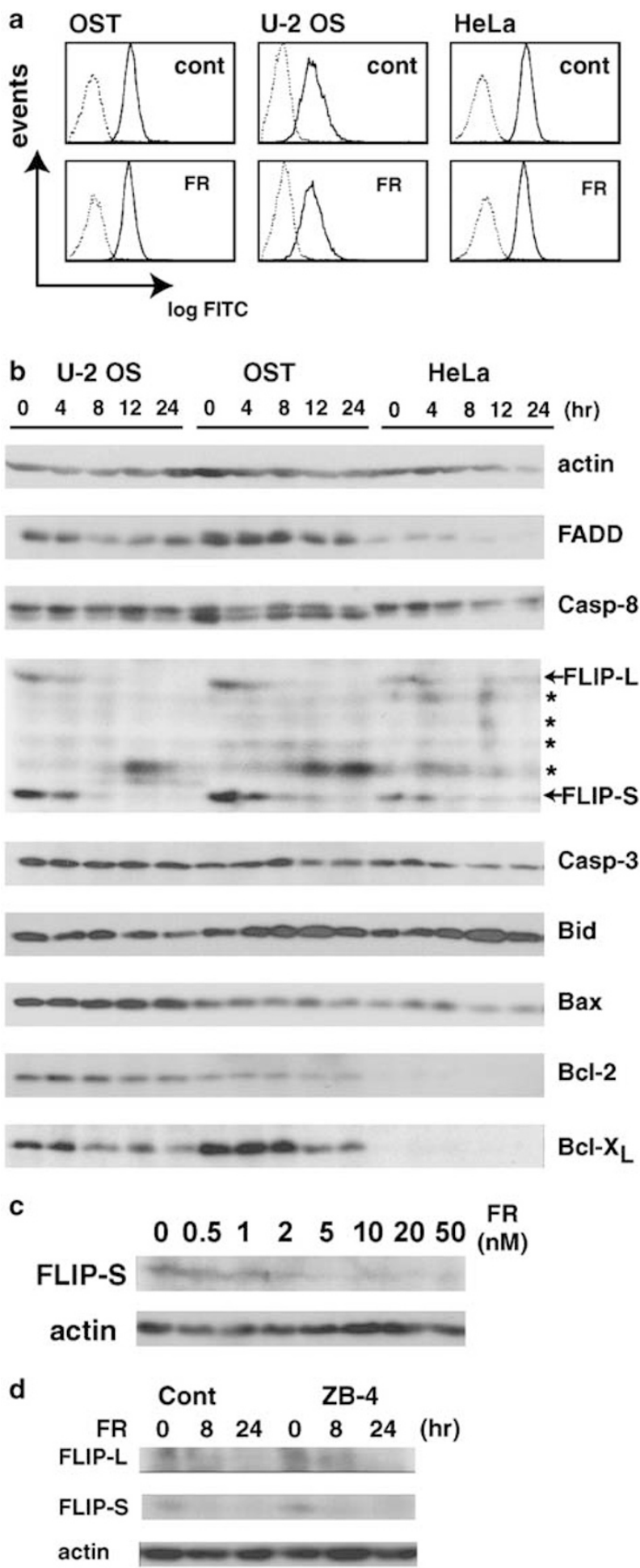

not only sensitized OST cells to Fas-induced apoptosis but also to TNF-related apoptosis-inducing ligand (TRAIL)-induced apoptosis (Figure 4d)

We also carried out Terminal Deoxynucleotidyltransferasemediated dUTP Nick End Labeling (TUNEL) assay for detecting apoptotic cells in GFP-positive cells, which were enriched by a cell sorter after the cotransfection with expression vectors for GFP and the RNAi constructs against FLIP (Figure 4e and f). RNAi-induced downregulation of FLIP$S$ and FLIP-L clearly sensitized OST cells to Fas-mediated apoptosis, and the sensitivity was indicated to be comparable to that of cells pretreated with FR901228. These results showed that downregulation of FLIP by either RNAi or HDAC inhibitors is sufficient to sensitize Fas-resistant osteosarcomaderived OST cells to Fas-induced apoptosis.

\section{FR901228 induces downregulation of FLIP mRNA}

It has recently been demonstrated that the level of cellular FLIP can be modulated not only by regulation of the transcription but also by degradation at the protein level through the ubiquitin-proteasome pathway. ${ }^{24-26}$ To clarify whether FR901228-induced downregulation of FLIP is caused by degradation of FLIP protein or decreased FLIP mRNA expression, Northern blot analysis was carried out on OST, U-2 OS, and HeLa cells treated with FR901228, and compared to a similar analysis of untreated cells (Figure $5 \mathrm{a}$ ). The results showed that treatment with FR901228 notably decreases the expression level of mRNA for both FLIP-S and FLIP-L. This indicates that treatment with FR901228 sensitized the tumor cell lines to Fas-mediated apoptosis by downregulating FLIP mRNA.

Since it is well known that HDAC inhibitors activate the transcription of a certain set of genes, ${ }^{5}$ we examined whether FR901228-induced downregulation of FLIP mRNA expression was mediated by de novo protein synthesis. OST cells were pretreated with $10 \mu \mathrm{g} / \mathrm{ml}$ cycloheximide for $1 \mathrm{~h}$, followed by cultivation with FR901228 in the presence of cycloheximide for $12 \mathrm{~h}$. As shown in Figure $5 \mathrm{a}$, treatment with cycloheximide did not inhibit the FR901228-induced downregulation of FLIP mRNA expression, indicating that this process is not dependent on de novo protein synthesis. To confirm that the concentration of cycloheximide $(10 \mu \mathrm{g} / \mathrm{ml})$ was sufficient to suppress protein synthesis, we quantified $\left[{ }^{35} \mathrm{~S}\right]$ methionine

Figure 3 Effect of FR901228 on the expression level of proteins involved in Fas-mediated apoptosis. (a) Flow cytometric analysis of Fas expression on OST, U-2 OS, and HeLa cells. Cells were cultured with (FR) or without (cont) $10 \mathrm{nM}$ FR901228 for $12 \mathrm{~h}$. Cells were stained with (solid line) or without (dotted line) mouse anti-Fas mAb ZB-4 and then with FITC-conjugated anti-mouse IgG Ab. (b) After treatment with $10 \mathrm{nM}$ FR901228 for the indicated time, the expression levels of FADD, caspase-8 (Casp-8), FLIP, caspase-3 (Casp-3), Bid, Bax, Bcl-2, $\mathrm{Bcl}-\mathrm{X}_{\mathrm{L}}$, and actin in OST, U-2 OS, and HeLa cells were analyzed by Western blotting. *, nonspecific bands. (c) After $12 \mathrm{~h}$ treatment with the indicated concentration of FR901228, the expression of levels of FLIP-S and actin were analyzed in OST cells by Western blotting. (d) After $1 \mathrm{~h}$ pretreatment with (ZB-4) or without (Cont) $500 \mathrm{ng} / \mathrm{ml}$ anti-Fas mAb ZB-4, which inhibits binding of FasL to Fas, OST cells were cultured with $10 \mathrm{nM}$ FR901228 in the presence (ZB-4) or absence (Cont) of ZB-4 for the indicated time. Then, the expression levels of FLIP-L, FLIP-S, and actin were analyzed in OST cells by Western blotting 
incorporation in OST cells in the presence or absence of cycloheximide and FR901228. The results showed that $10 \mu \mathrm{g} /$ $\mathrm{ml}$ cycloheximide or $10 \mu \mathrm{g} / \mathrm{ml}$ cycloheximide plus $10 \mathrm{nM}$ FR901228 decreased protein synthesis by 6.5 and $6.6 \%$, respectively, compared to that in the absence of cycloheximide.

a

b
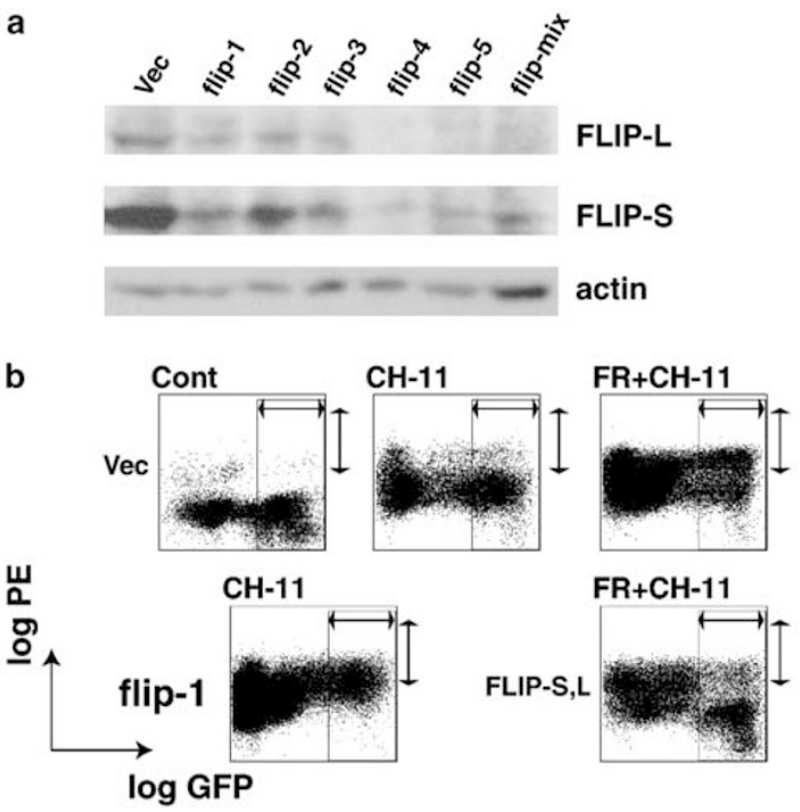

C
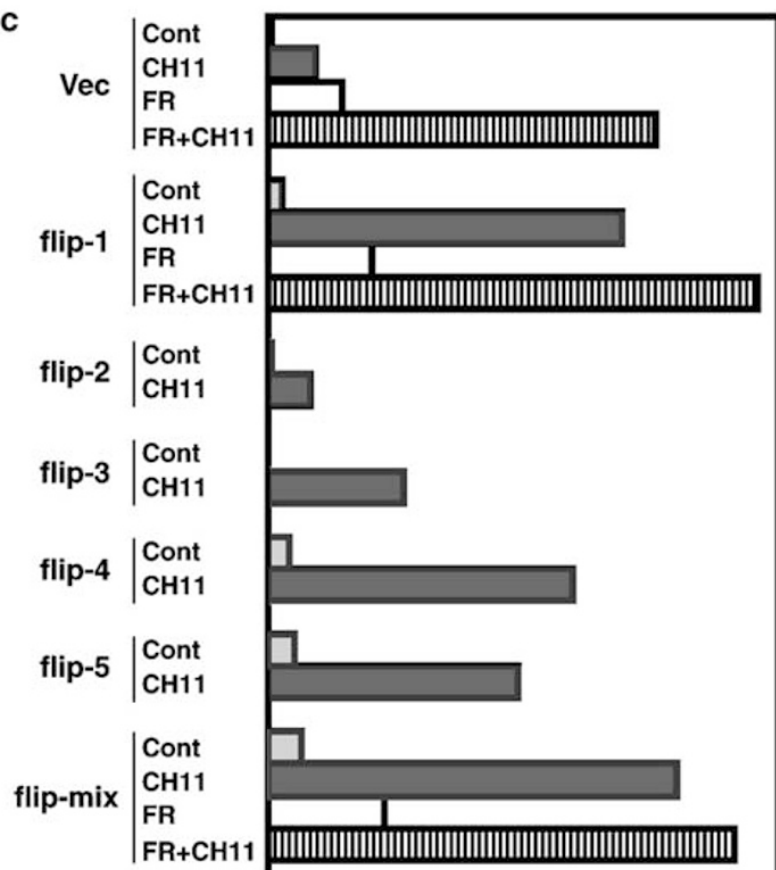

FLIP-S,L

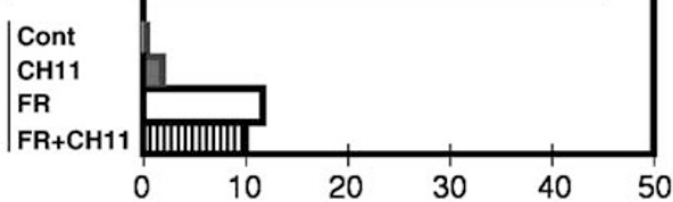

(\%)
We then examined whether the FR901228-induced downregulation of FLIP was caused by reduction of RNA synthesis or stimulation of RNA degradation. Northern blot analysis was performed in OST cells pretreated with $1 \mu \mathrm{g} / \mathrm{ml}$ actinomycin D for $1 \mathrm{~h}$ and cultured with or without FR901228 in the presence of actinomycin $D$ for 4 or $12 \mathrm{~h}$. As shown in Figure $5 \mathrm{~b}$, the

d
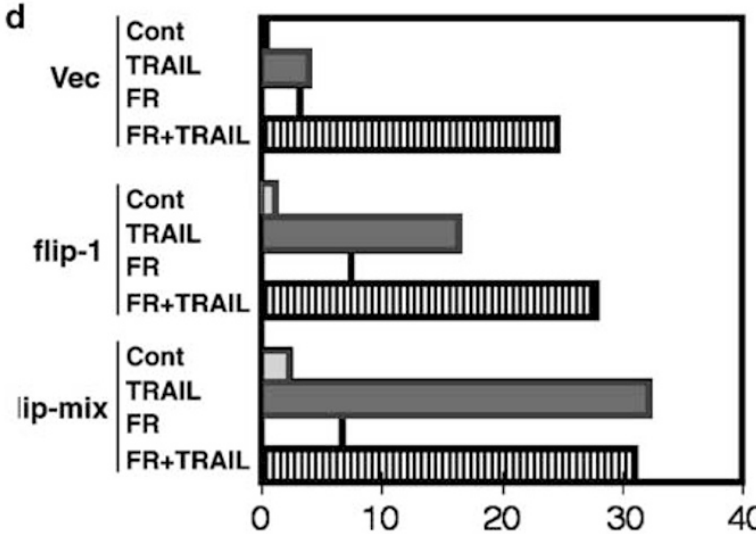

(\%)

e
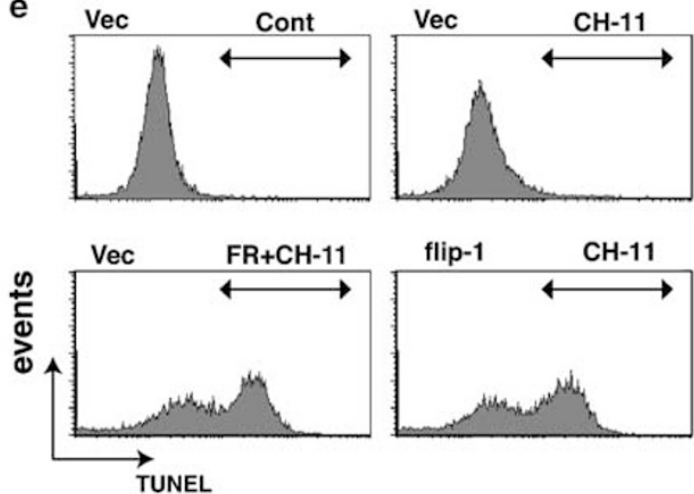

f

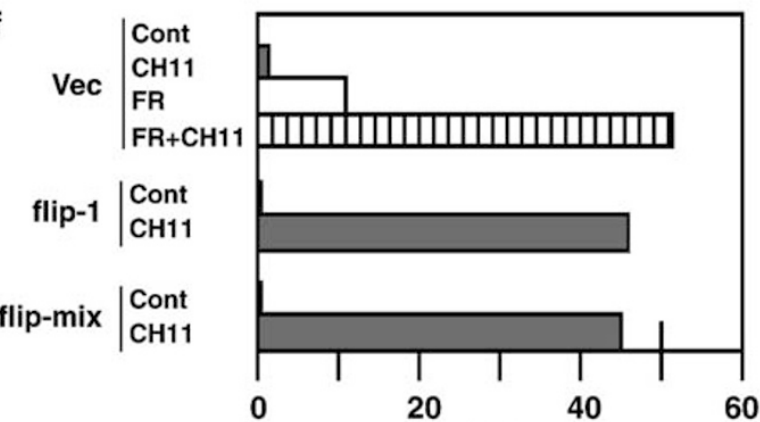

(\%) 
amount of FLIP mRNA rapidly decreased following treatment with actinomycin $\mathrm{D}$ alone, and the combination of actinomycin $\mathrm{D}$ and FR901228 did not cause a greater reduction of the FLIP-S mRNA level, compared with cells treated with actinomycin $\mathrm{D}$ alone. To confirm that the concentration of actinomycin D $(1 \mu \mathrm{g} / \mathrm{ml})$ was sufficient to suppress RNA synthesis, we quantified $\left[{ }^{3} \mathrm{H}\right]$ uridine incorporation into RNA in OST cells in the presence or absence of actinomycin $D$ and FR901228. The results showed that $1 \mu \mathrm{g} / \mathrm{ml}$ actinomycin D or $1 \mu \mathrm{g} / \mathrm{ml}$ actinomycin D plus $10 \mathrm{nM}$ FR901228 decreased RNA synthesis by $1.0 \%$ compared to that in the absence of actinomycin $\mathrm{D}$. This suggests that a reduction of new FLIP mRNA synthesis is induced by treatment with FR901228, and that this is sufficient to decrease the FLIP-S mRNA level.

To examine whether the downregulation of FLIP mRNA by treatment with FR901228 is dependent on FR901228induced inhibition of HDAC activity, the effects of other classes of HDAC inhibitors were analyzed. The expression level of FLIP mRNA was analyzed by Northern blot hybridization in cells treated with either $10 \mathrm{nM}$ Trichostatin $A$ or $20 \mathrm{mM}$ sodium butyrate. This showed that treatment of OST cells with various types of HDAC inhibitors also decreases FLIP mRNA expression, as observed in FR901128-treated cells (Figure $5 b$ ).

We then examined whether treatment of OST cells with FR901228 induces degradation of FLIP protein. The expression level of FLIP-S protein was quantified by Western blotting in OST cells treated with cycloheximide in the presence or absence of FR901228 (Figure 5c). FLIP-S protein was shown to be rapidly downregulated in the presence of cycloheximide, and FR901228 did not affect the rapid downregulation of FLIP-S protein. Thus, FR901228 does not induce degradation of FLIP protein, and FR901228-induced downregulation of FLIP mRNA is sufficient to cause the downregulation of FLIP. Therefore, we conclude that inhibition of HDAC activity sensitizes tumor cell lines to Fas-induced apoptosis by downregulation of FLIP through inhibition of transcription of FLIP mRNA.

\section{Discussion}

Although the synergistic induction of apoptosis has been previously reported for the simultaneous stimulation of death receptors with HDAC inhibitors, ${ }^{23,27-29}$ the data in this manuscript indicate that pretreatment with the HDAC inhibitor
FR901228 causes sensitization to Fas-mediated apoptosis through suppression of FLIP mRNA expression. In addition, downregulation of FLIP by RNAi was shown to be sufficient to sensitize death receptor-resistant OST cells to Fas- and TRAIL-induced apoptosis. All the data clearly indicate that the HDAC inhibitor FR901228 renders Fas-resistant tumor cells sensitive to Fas-induced apoptosis by downregulating FLIP mRNA through inhibition of its transcription.

We also analyzed the effect of two other classes of HDAC inhibitors, Trichostatin A and butyrate, and showed that they can similarly decrease the FLIP mRNA level (Figure 5b) and sensitize OST cells to Fas-induced apoptosis (data not shown). Therefore, the effect of FR901228 may be based on its HDAC inhibitory activity. While HDAC inhibitors are generally regarded as transcriptional activators, we demonstrated that FR901228 downregulates FLIP mRNA through suppression of its generation that is independent of de novo protein synthesis (Figure $5 \mathrm{a}$ and b). In addition, FR901228 did not enhance the degradation of FLIP protein (Figure $5 \mathrm{c}$ ). Thus, FR901228 might directly induce inhibition of FLIP gene transcription. Interestingly, HDAC inhibitors have been suggested to induce both activation and suppression of transcription, since treatment with such inhibitors causes the upregulation and downregulation of an approximately equal numbers of genes. ${ }^{30}$ Therefore, our result showing that FR901228 induces transcriptional downregulation of FLIP without de novo protein synthesis is plausible, but its mechanism remains an open question.

Previous reports have shown HDAC inhibitor-induced upregulation of $\mathrm{Fas}^{18-20} \mathrm{FasL}^{23}$ and $\mathrm{Bax}^{31}$ and downregulation of $\mathrm{Bcl}-\mathrm{X}_{\mathrm{L}}{ }^{29,32}$ On the contrary, we did not observe changes in Fas and $\mathrm{Bcl}-\mathrm{X}_{\mathrm{L}}$ expression following treatment of OST, U-2 OS, and HeLa cells with FR901228 (Figure 3b). The difference between previous reports and our results may be due to cell type-specific effects. However, we believe that downregulation of FLIP by HDAC inhibitors may be a more general effect than the regulation of Fas, FasL, Bax, and $\mathrm{Bcl}-$ $X_{L}$, since we observed FR901228-induced downregulation of FLIP in embryonic fibroblasts and T-lymphoma cell lines, as well as in OST, U-2 OS, and HeLa cells (Figure $3 b$ and data not shown). We note that previously reported gene expression profile experiments have not shown HDAC inhibitor-induced downregulation of FLIP mRNA, ${ }^{30,33,34}$ suggesting that the basal level of FLIP mRNA was not high enough for detection under the experimental conditions used in these studies.

Figure 4 Suppression of FLIP expression is sufficient to sensitize OST cells to Fas-induced apoptosis. (a) OST cells were transfected with a puromycin-resistant vector together with pSUPER vectors for RNAi against FLIP; pSUPER flip-1, -2, -3, -4, -5, flip-mix, or an empty vector (Vec). After incubation for $24 \mathrm{~h}$, cells were treated with $10 \mu \mathrm{g} / \mathrm{ml}$ puromycin for $24 \mathrm{~h}$. Dead cells were removed by washing with PBS and the remaining adherent cells (vector-transfected cells) were analyzed by Western blotting with anti-FLIP antibody and anti-actin antibody. (b-d) OST cells were transfected with GFP expression vector together with pSUPER vectors for RNAi against FLIP; flip-1, -2, -3, -4, -5, flip-mix, or empty vector (Vec) or with expression vectors for FLIP-S and FLIP-L (FLIP-S, L). Cells were cultured for $24 \mathrm{~h}$, treated or not treated with $10 \mathrm{nM}$ FR901228 (FR or control, respectively), and then stimulated with $250 \mathrm{ng} / \mathrm{ml} \mathrm{CH}-11$ (b and c) or $200 \mathrm{ng} / \mathrm{ml}$ TRAlL (d) for $12 \mathrm{~h}$. Activated caspase-3 (cleaved form) was detected by flow cytometry using anti-cleaved caspase-3-PE antibody. GFP-positive regions or caspase-3-active regions are indicated by bold lines with arrowheads (b). The number of GFP-positive cells with activated caspase-3 is shown as a percentage of the total GFP-positive cells (c and d). At least $1 \times 10^{4}$ GFPpositive cells were analyzed for each sample. Representative data are shown from at least three independent experiments. (e and f) OST cells were transfected with GFP expression vector together with pSUPER vectors for RNAi against FLIP. GFP-positive cells were highly enriched by cell-sorting $20 \mathrm{~h}$ after the transfection. The sorted cells were pretreated with $10 \mathrm{nM}$ FR901228 for $12 \mathrm{~h}$, and then stimulated with $250 \mathrm{ng} / \mathrm{ml} \mathrm{CH}-11$ for $15 \mathrm{~h}$. Apoptotic cells were detected by TUNEL method as described in Materials and Methods, and TUNEL-positive cells were detected by flow cytometry (e). TUNEL-positive regions are indicated by bold lines with arrowheads. The percentage of TUNEL-positive cells is shown as a percentage of the total GFP-positive cells (f). Representative data are shown from at least three independent experiments 
a

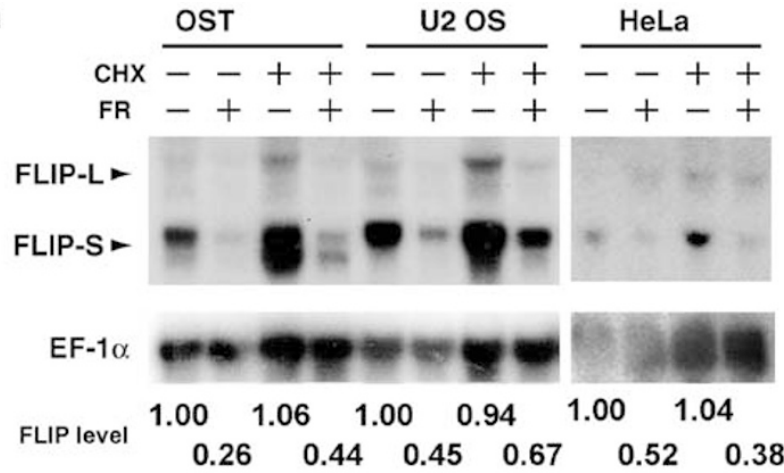

b

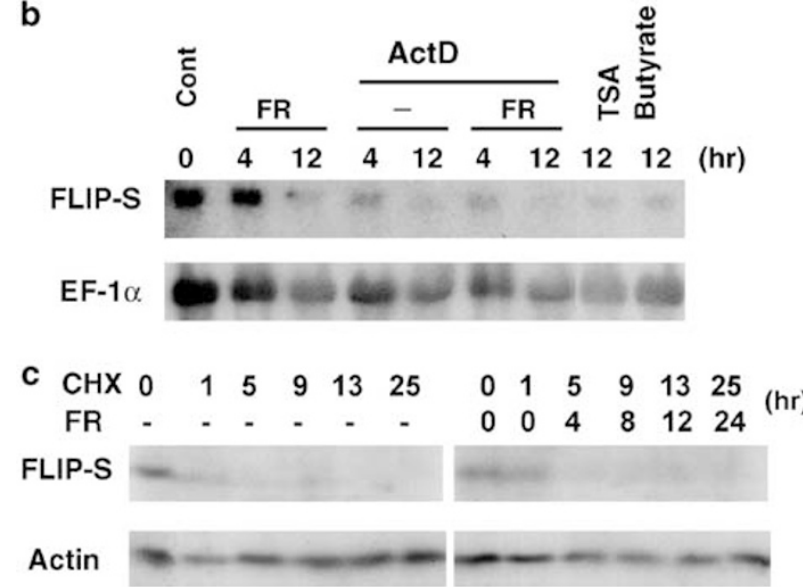

Figure 5 FR901228-induced downregulation of FLIP mRNA and its effect on FLIP protein expression. (a) After pretreatment with or without $10 \mu \mathrm{g} / \mathrm{ml}$ cycloheximide (CHX) for $1 \mathrm{~h}, \mathrm{OST}, \mathrm{U}-2 \mathrm{OS}$, and HeLa cells were cultured with or without $10 \mathrm{nM}$ FR901228 (FR) for $12 \mathrm{~h}$ in the presence or absence of CHX. RNA was extracted, and Northern blot analyses for FLIP and EF1 $\alpha$ mRNA were carried out. FLIP level indicates the ratio of quantified amounts of FLIP-S mRNA to those of control cells not treated with $\mathrm{FR}$ or $\mathrm{CHX}$, which were normalized with those of EF $1 \alpha$ mRNA. (b) After pretreatment with or without $1 \mu \mathrm{g} / \mathrm{ml}$ actinomycin $\mathrm{D}$ for $1 \mathrm{~h}$, OST cells were cultured with or without $10 \mathrm{nM}$ FR901228, $10 \mathrm{nM}$ Trichostatin A (TSA), or $20 \mathrm{mM}$ sodium butyrate (butyrate) for $12 \mathrm{~h}$ in the presence or absence of actinomycin $D$, and then Northern blot analysis was performed as described in (a). (c) After pretreatment with or without $10 \mu \mathrm{g} / \mathrm{ml}$ $\mathrm{CHX}$ for $1 \mathrm{~h}$, OST cells were cultured with or without $10 \mathrm{nM}$ FR901228 for the indicated time in the presence of CHX. Then, the expression levels of FLIP-S and actin were analyzed by Western blotting

Some classes of HDAC inhibitors are under clinical development, since they have anticancer effects in a variety of cancer cells. ${ }^{6}$ Death receptor-induced apoptosis by recombinant TRAIL ${ }^{35}$ or agonistic anti-Fas mAb without indication of hepatotoxicity ${ }^{36}$ has also been explored as a cancer therapy. Many tumor cells are, however, resistant to Fas-mediated apoptosis, despite the cell-surface expression of $\mathrm{Fas}^{37}$ Here, we have demonstrated that FR901228 renders Fas-resistant OST and U-2 OS cells sensitive to Fas-induced apoptosis by downregulating FLIP. The expression levels of FLIP-S and FLIP-L in these cells were not especially high compared to other tumor cells (data not shown), and downregulation of FLIP by RNAi was clearly shown to be sufficient to confer sensitivity to death receptormediated apoptosis in OST cells (Figure 4). These results suggest that the synergistic effect of combination treatment with an HDAC inhibitor and a death-receptor-stimulant, or with FLIP antagonists including FLIP RNAi and a death-receptorstimulant may not be specific to the restricted number of cell lines examined here, but may be general over a broad range of tumor cells. In fact, HeLa cells, in which both p53 and Rb are functionally defective, as observed in many tumor cells, showed much higher sensitivity to Fas-induced apoptosis following treatment with FR901228 (Figure 1), with associated downregulation of FLIP (Figure $3 \mathrm{~b}$ and 5). Our proposed molecular mechanism of synergistic induction of apoptosis by death receptor stimulation and HDAC inhibitor treatment may open the door to combination cancer therapy using this approach.

\section{Materials and Methods}

\section{Cell lines}

Human osteosarcoma cell lines, OST and U-2 OS, and human adenocarcinoma-derived HeLa cells were provided by Dr Souichi Adachi (Graduate School of Medicine, Kyoto University) and Dr Yoshihide Tsujimoto (Osaka University Medical School), respectively. Cells were maintained in Dulbecco's modified Eagle's medium (DMEM) (Nacalai Tesque) containing $10 \%$ heat-inactivated fetal bovine serum, $100 \mathrm{U}$ penicillin, and $100 \mu \mathrm{g} / \mathrm{ml}$ streptomycin at $37^{\circ} \mathrm{C}$ in $5 \% \mathrm{CO}_{2}$.

\section{Reagents and antibodies}

FR901228 was a gift from Fujisawa Pharmaceutical Co. Ltd., Japan. Agonistic anti-Fas mAb CH-11 and antagonistic anti-Fas mAb ZB4 were obtained from Medical and Biological Laboratories (MBL), Japan. AntiFLIP mAb Dave-2, mouse anti-actin mAb MAB1501R, and goat anti-rat IgG antibody were purchased from Alexis Biochemicals, Chemicon International and Santa Cruz Biotechnology, respectively. Anti-caspase$8 \mathrm{mAb} 1 \mathrm{C} 12$, anti-caspase- 9 antibody, anti-caspase-3 antibody, anti-Bid antibody, anti-Bax antibody, and anti-mouse IgG antibody were purchased from Cell Signaling Technology. Anti-Bcl-2 antibody and anti-Bcl- $X_{L} m A b$ were purchased from BD Biosciences. Z-VAD-fmk was purchased from Peptide institute, Inc., Japan. Cycloheximide and actinomycin D were purchased from Nacalai Tesque, Inc., Japan.

\section{DNA content analysis for detection of apoptosis}

Cells in which apoptosis had been induced were harvested, washed with PBS and fixed in $70 \%$ ethanol for at least $2 \mathrm{~h}$ at $-30^{\circ} \mathrm{C}$. After washing with PBS, cells were treated with PBS containing $0.25 \mathrm{mg} / \mathrm{ml}$ RNase at $37^{\circ} \mathrm{C}$ for $15 \mathrm{~min}$ and then incubated with $50 \mu \mathrm{g} / \mathrm{ml}$ propidium iodide (PI) at $4^{\circ} \mathrm{C}$ for $30 \mathrm{~min}$ in the dark. Cells were analyzed with an EPICS $\mathrm{XL}^{\mathrm{TM}}$ Flow Cytometer (Beckman Coulter). Subdiploid (sub-G1) populations were calculated as an estimate of the apoptotic cell population.

\section{Western blot analysis}

Cells were lysed in cold lysis buffer $(50 \mathrm{mM}$ Tris- $\mathrm{HCl}$, pH 8.0 with $10 \%$ glycerol, $1 \%$ Nonidet P-40, $50 \mathrm{mM} \mathrm{NaCl}, 2 \mathrm{mM}$ EDTA, and $1 \mathrm{mM} \mathrm{DTT)}$ containing $1 \%(\mathrm{v} / \mathrm{v})$ of protease inhibitor cocktail (Sigma) and $1 \mathrm{mM}$ PMSF. Cell lysate was centrifuged at 15000 r.p.m. for $20 \mathrm{~min}$ and the resulting supernatant was resolved by SDS-PAGE and transferred to an Immobilon transfer membrane (Millipore). The immunoblotting assay was performed 
using a specific primary antibody and a peroxidase-conjugated secondary antibody, as described previously. ${ }^{38}$

\section{RNA interference analysis for FLIP}

The pSUPER RNAi system (OligoEngine) was used in RNA interference suppression of FLIP expression. Five kinds of pSUPER vectors were designed, and these are referred to as pSUPER flip-1, $-2,-3,-4$, and -5 . These included 19-nucleotide sequences of FLIP cDNA starting at nucleotide (nt) 139, nt 140, nt 172, nt 230, and nt 258, respectively, and all sequences were common to both FLIP-S and FLIP-L cDNA. pSUPER flipmix refers to a mixture of flip- $-1,-4$, and -5 .

\section{Analysis of caspase-3 activation in various transfectants}

Cells in six-well plates were transfected with $0.2 \mu \mathrm{g}$ expression vector for EGFP $^{39}$ together with $0.8 \mu \mathrm{g}$ pSUPER vector for RNAi against FLIP or with pCMV-Tag2B (Stratagene) encoding FLIP-S $(0.025 \mu \mathrm{g})$ and FLIP-L $(0.025 \mu \mathrm{g})$ using Lipofectamine Plus (Invitrogen), in accordance with the manufacturer's instructions. The total amount of DNA for each transfection was adjusted to $1.0 \mu \mathrm{g}$ per sample by adding empty vector. After incubation for $24 \mathrm{~h}$, cells were pretreated for $12 \mathrm{~h}$ with $10 \mathrm{nM}$ FR901228 in the culture medium and then stimulated with $250 \mathrm{ng} / \mathrm{ml}$ anti-Fas $\mathrm{mAb} \mathrm{CH}$ 11 or $250 \mathrm{ng} / \mathrm{ml}$ TRAIL. Cells were permeabilized, fixed, and then stained with phycoerythrin (PE)-conjugated anti-active caspase-3 mAb (BD Bioscience), in accordance with the manufacturer's instructions. GFPpositive cells (vector-transfected cells) and PE-positive cells (caspase-3active cells) were simultaneously analyzed by flow cytometry.

\section{TUNEL assay}

Cells in $100 \mathrm{~mm}$ dishes were transfected with GFP expression vector together with pSUPER vectors for RNAi against FLIP. After $20 \mathrm{~h}$ of cultivation, GFP-positive cells were highly enriched by a cell sorter, MoFlo flow Cytometer (Cytomation). Subsequently, cells were washed twice with culture medium and plated. After $5 \mathrm{~h}$ cultivation, adherent cells were treated for $12 \mathrm{~h}$ with $10 \mathrm{nM}$ FR901228, and then stimulated with $250 \mathrm{ng} / \mathrm{ml}$ anti-Fas $\mathrm{mAb} \mathrm{CH}-11$ for $15 \mathrm{~h}$. DNA nick ends in cells were labeled with biotinylated dUTP by terminal deoxynucleotidyl transferase and then stained with streptavidin-PE using MEBSTATIN Apoptosis Kit 2 (MBL, Japan).

\section{Northern blot analysis}

RNA was isolated from cells using Isogen (Nippongene, Tokyo, Japan) and Northern hybridization was performed, as described previously, ${ }^{40}$ using full-length human FLIP cDNA, which recognizes nt 1-666 of FLIP-S and nt 1-609 of FLIP-L, and full-length human EF1 $\alpha$ CDNA as probes for detection of FLIP and EF1 $\alpha$ mRNA, respectively.

\section{Acknowledgements}

We thank A Murakami, M Ohgushi, T Tsubata, T Adachi, Y Nakatsumi, and S Adachi for their generous help and KK Lee and K Sakamaki for their helpful comments. This work was supported in part by Grants-in-Aid from the Ministry of Education, Culture, Sports, Science and Technology of the Japanese Government.

\section{References}

1. Rinkenberger $\mathrm{J}$ and Korsmeyer $\mathrm{S}$ (1997) Errors of homeostasis and deregulated apoptosis. Curr. Opin. Genet. Dev. 7: 589-596

2. Meier P, Finch A and Evan G (2000) Apoptosis in development. Nature 407: 796-801

3. Rich T, Allen R and Wyllie A (2000) Defying death after DNA damage. Nature 407: 777-783

4. Marmorstein R and Roth SY (2001) Histone acetyltransferases: function, structure, and catalysis. Curr. Opin. Genet. Dev. 11: 155-161

5. $\mathrm{Ng} \mathrm{HH}$ and Bird A (2000) Histone deacetylases: silencers for hire. Trends Biochem. Sci. 25: 121-126

6. Johnstone RW (2002) Histone-deacetylase inhibitors: novel drugs for the treatment of cancer. Nat. Rev. Drug. Discov. 1: 287-299

7. Ueda H, Nakajima H, Hori Y, Fujita T, Nishimura M, Goto T and Okuhara M (1994) FR901228, a novel antitumor bicyclic depsipeptide produced by Chromobacterium violaceum No. 968. I. Taxonomy, fermentation, isolation, physico-chemical and biological properties, and antitumor activity. J. Antibiot (Tokyo). 47: 301-310

8. Shigematsu N, Ueda H, Takase S, Tanaka H, Yamamoto K and Tada T (1994) FR901228, a novel antitumor bicyclic depsipeptide produced by Chromobacterium violaceum No. 968. II. Structure determination. J. Antibiot (Tokyo). 47: 311-314

9. Ueda H, Manda T, Matsumoto S, Mukumoto S, Nishigaki F, Kawamura I and Shimomura K (1994) FR901228, a novel antitumor bicyclic depsipeptide produced by Chromobacterium violaceum No. 968. III. Antitumor activities on experimental tumors in mice. J. Antibiot (Tokyo). 47: 315-323

10. Ueda H, Nakajima H, Hori Y, Goto T and Okuhara M (1994) Action of FR901228, a novel antitumor bicyclic depsipeptide produced by Chromobacterium violaceum no. 968, on Ha-ras transformed NIH3T3 cells. Biosci. Biotechnol. Biochem. 58: 1579-1583

11. Cory S and Adams JM (2002) The Bcl2 family: regulators of the cellular life-ordeath switch. Nat. Rev. Cancer 2: 647-656

12. Schneider $P$ and Tschopp J (2000) Apoptosis induced by death receptors. Pharm. Acta Helv. 74: 281-286

13. Itoh N, Yonehara S, Ishii A, Yonehara M, Mizushima S, Sameshima M, Hase A, Seto $Y$ and Nagata S (1991) The polypeptide encoded by the cDNA for human cell surface antigen Fas can mediate apoptosis. Cell 66: 233-243

14. Nagata S (1997) Apoptosis by death factor. Cell 88: 355-365

15. Yonehara S, Ishii A and Yonehara M (1989) A cell-killing monoclonal antibody (anti-Fas) to a cell surface antigen co-downregulated with the receptor of tumor necrosis factor. J. Exp. Med. 169: 1747-1756

16. Walczak $\mathrm{H}$ and Krammer PH (2000) The CD95 (APO-1/Fas) and the TRAIL (APO-2L) apoptosis systems. Exp. Cell Res. 256: 58-66

17. Irmler M, Thome M, Hahne M, Schneider P, Hofmann K, Steiner V, Bodmer JL, Schroter M, Burns K, Mattmann C, Rimoldi D, French LE and Tschopp J (1997) Inhibition of death receptor signals by cellular FLIP. Nature 388: 190-195

18. Glick RD, Swendeman SL, Coffey DC, Rifkind RA, Marks PA, Richon VM and La Quaglia MP (1999) Hybrid polar histone deacetylase inhibitor induces apoptosis and CD95/CD95 ligand expression in human neuroblastoma. Cancer Res. 59: 4392-4399

19. Kwon SH, Ahn SH, Kim YK, Bae GU, Yoon JW, Hong S, Lee HY, Lee YW, Lee HW and Han JW (2002) Apicidin, a histone deacetylase inhibitor, induces apoptosis and Fas/Fas ligand expression in human acute promyelocytic leukemia cells. J. Biol. Chem. 277: 2073-2080

20. Klisovic DD, Katz SE, Effron D, Klisovic MI, Wickham J, Parthun MR, Guimond $M$ and Marcucci G (2003) Depsipeptide (FR901228) inhibits proliferation and induces apoptosis in primary and metastatic human uveal melanoma cell lines. Invest. Ophthalmol. Vis. Sci. 44: 2390-2398

21. Aron JL, Parthun MR, Marcucci G, Kitada S, Mone AP, Davis ME, Shen T, Murphy T, Wickham J, Kanakry C, Lucas DM, Reed JC, Grever MR and Byrd JC (2003) Depsipeptide (FR901228) induces histone acetylation and inhibition of histone deacetylase in chronic lymphocytic leukemia cells concurrent with activation of caspase 8-mediated apoptosis and down-regulation of c-FLIP protein. Blood 102: 652-658

22. Lucas DM, Davis ME, Parthun MR, Mone AP, Kitada S, Cunningham KD, Flax EL, Wickham J, Reed JC, Byrd JC and Grever MR (2004) The histone deacetylase inhibitor MS-275 induces caspase-dependent apoptosis in B-cell chronic lymphocytic leukemia cells. Leukemia 18: 1207-1214 
23. Imai T, Adachi S, Nishijo K, Ohgushi M, Okada M, Yasumi T, Watanabe K, Nishikomori R, Nakayama T, Yonehara S, Toguchida J and Nakahata T (2003) FR901228 induces tumor regression associated with induction of Fas ligand and activation of Fas signaling in human osteosarcoma cells. Oncogene 22: 9231-9242

24. Fukazawa T, Fujiwara T, Uno F, Teraishi F, Kadowaki Y, Itoshima T, Takata $Y$, Kagawa S, Roth JA, Tschopp J and Tanaka N (2001) Accelerated degradation of cellular FLIP protein through the ubiquitin-proteasome pathway in p53mediated apoptosis of human cancer cells. Oncogene 20: 5225-5231

25. Kim Y, Suh N, Sporn M and Reed JC (2002) An inducible pathway for degradation of FLIP protein sensitizes tumor cells to TRAIL-induced apoptosis. J. Biol. Chem. 277: 22320-22329

26. Perez D and White $E(2003) E 1 A$ sensitizes cells to tumor necrosis factor alpha by downregulating c-FLIP(S). J. Virol. 77: 2651-2662

27. Bernhard D, Skvortsov S, Tinhofer I, Hubl H, Greil R, Csordas A and Kofler R (2001) Inhibition of histone deacetylase activity enhances Fas receptormediated apoptosis in leukemic lymphoblasts. Cell Death Differ. 8: 1014-1021

28. Bonnotte B, Favre N, Reveneau S, Micheau O, Droin N, Garrido C, Fontana A, Chauffert B, Solary E and Martin F (1998) Cancer cell sensitization to fasmediated apoptosis by sodium butyrate. Cell Death Differ. 5: 480-487

29. Neuzil J, Swettenham E and Gellert N (2004) Sensitization of mesothelioma to TRAIL apoptosis by inhibition of histone deacetylase: role of Bcl-x(L) downregulation. Biochem. Biophys. Res. Commun. 314: 186-191

30. Chambers AE, Banerjee S, Chaplin T, Dunne J, Debernardi S, Joel SP and Young BD (2003) Histone acetylation-mediated regulation of genes in leukaemic cells. Eur. J. Cancer. 39: 1165-1175

31. Suzuki T, Yokozaki H, Kuniyasu H, Hayashi K, Naka K, Ono S, Ishikawa T, Tahara E and Yasui W (2000) Effect of trichostatin A on cell growth and expression of cell cycle- and apoptosis-related molecules in human gastric and oral carcinoma cell lines. Int. J. Cancer 88: 992-997
32. Cao XX, Mohuiddin I, Ece F and McConkey DJ andSmythe WR. (2001) Histone deacetylase inhibitor downregulation of bcl-xl gene expression leads to apoptotic cell death in mesothelioma. Am. J. Respir. Cell Mol. Biol. 25: 562-568

33. Mariadason JM, Corner GA and Augenlicht LH (2000) Genetic reprogramming in pathways of colonic cell maturation induced by short chain fatty acids: comparison with trichostatin A, sulindac, and curcumin and implications for chemoprevention of colon cancer. Cancer Res. 60: 4561-4572

34. Glaser KB, Staver MJ, Waring JF, Stender J, Ulrich RG and Davidsen SK (2003) Gene expression profiling of multiple histone deacetylase (HDAC) inhibitors: defining a common gene set produced by HDAC inhibition in T24 and MDA carcinoma cell lines. Mol. Cancer Ther. 2: 151-163

35. de Jong S, Timmer T, Heijenbrok FJ and de Vries EG (2001) Death receptor ligands, in particular TRAIL, to overcome drug resistance. Cancer Metasta. Rev. 20: 51-56

36. Yonehara S (2002) Death receptor Fas and autoimmune disease: from the original generation to therapeutic application of agonistic anti-Fas monoclonal antibody. Cytokine Growth Factor Rev. 13: 393-402

37. French LE and Tschopp J (2002) Defective death receptor signaling as a cause of tumor immune escape. Semin. Cancer Biol. 12: 51-55

38. Lee KK, Ohyama T, Yajima N, Tsubuki S and Yonehara S (2001) MST, a physiological caspase substrate, highly sensitizes apoptosis both upstream and downstream of caspase activation. J. Biol. Chem. 276: 19276-19285

39. Ogawa H, Inouye S, Tsuji FI, Yasuda K and Umesono K (1995) Localization, trafficking, and temperature-dependence of the Aequorea green fluorescent protein in cultured vertebrate cells. Proc. Natl. Acad. Sci. USA 92: 1189911903

40. Murakami A, Thurlow J and Dickson C (1999) Retinoic acid-regulated expression of fibroblast growth factor 3 requires the interaction between a novel transcription factor and GATA-4. J. Biol. Chem. 274: 17242-17248 